\title{
Internet Penetration and Capacity Utilization in the US Airline Industry*
}

\author{
James D. Dana, Jr. \\ Eugene Orlov \\ Northeastern University \\ Compass Lexecon
}

February 24, 2008

\begin{abstract}
Airline capacity utilization, or load factors, increased dramatically between 1993 and 2007, after staying fairly level for the first 15 years following deregulation. Improvements in demand forecasting, capacity management, and revenue management are potential explanations, but revenue management systems were widely adopted in the 1980's, significantly before the increase in load factor. We argue that consumers' adoption of the Internet, and their use of the Internet to investigate and purchase airline tickets, explains recent increases in airlines' load factors. Using metropolitan area measures of Internet penetration, we find strong evidence that differences in the rate of change of Internet penetration explain differences in the rate of change of airline airportpair load factors. We argue that these increases, and a significant part of the associated $\$ 1$ billion reduction in airlines' annual costs, represent a previously unmeasured social welfare benefit of the Internet.
\end{abstract}

${ }^{*}$ We would like to thank Shane Greenstein, Bruce Meyer, Kathryn Spier and Scott Stern for extremely helpful comments. Jim Dana is a professor of economics and strategy at Northeastern University. He is also a visiting scholar at Harvard Business School. He can be reached via e-mail at j.dana@neu.edu or jdana@hbs.edu. Eugene Orlov is an economist at Lexecon and can be reached via e-mail at eorlov@compasslexecon.com. 


\section{Introduction}

US airline industry domestic passenger load factors, or capacity utilization, have increased from $62 \%$ in 1993 to $80 \%$ in 2007 after ranging from $57 \%$ to $63 \%$ in the years since deregulation. One potential explanation is the use of sophisticated revenue management systems by airlines. These sophisticated data and capacity management systems help airlines to forecast demand, more efficiently utilize their aircraft and personnel resources, and create incentives for consumers to choose alternatives to purchasing seats on flights with scarce capacity, even when that capacity was not expected to be scarce. However, revenue management systems were widely adopted in the 1980's, not in the late 1990's.

Instead, we argue that the rapid increase in consumer Internet penetration in the late 1990's and early 2000's, and the associated increase in the use of the Internet as the primary method for investigating and booking airline reservations is responsible for much of the increase in load factors. The Internet has given consumers more information about available products including alternative departure times, alternative carriers, alternative airports, alternative legroom, and alternative in-flight durations (the number of stops), which makes it more likely that consumers will take advantage of incentives to travel on flights with excess capacity and more likely that airlines will find it profitable to offer those incentives. Consistent with this explanation, we find that changes in US metropolitan area Internet penetration rates explain changes in airlines' airport-pair load factors, dramatically reducing airlines' costs.

Until now, research on the economic impact of the Internet has focused on the impact of lower search costs on the level and dispersion of firms' prices. An obvious implication of lower search costs is increased price competition. While the impact on price levels can be dramatic (see, for example, Brynjolfsson and Smith, 2000), the increases in social welfare associated with price decreases are small. We look at the effect of the Internet on a more direct type of allocative efficiency: the improved utilization of existing goods and services as measured by airline load factors. We find that the elasticity of capacity utilization with respect to Internet penetration is .054 and that the increase in Internet penetration from 1997 to 2003 resulted in an estimated $2.6 \%$ increase in load factors or over $\$ 1$ billion in cost savings each year. We argue that at least half of this savings represents a social welfare gain.

Any attempt to measure the impact of the Internet on capacity utilization must address why capacity isn't being fully utilized in the first place. Most economic models assume either spot market pricing, or forward contracts, and conclude that excess capacity arises only when shadow cost of capacity is zero. However, this does not appear to be the main explanation for excess capacity in the airline industry. 
Some models in the economics literature, and most in the operations literature, predict capacity may not be fully utilized by introducing price rigidities. Indeed, casual observation suggests airlines typically do not adjust their prices significantly as a departure time approaches and certainly do not set market clearing prices ex post. Instead they set prices in advance and then use sophisticated software to manage the inventory available at each price. Setting prices in advance when demand is unknown can clearly result in allocative inefficiencies and lead to the underutilization of capacity.

We begin by presenting a simple stochastic peak-load pricing model based on Dana $(1999 \mathrm{a})^{1}$. In the model, airlines set prices prior to knowing the distribution of demand across flights. As in Dana (1999a) airlines offer multiple prices which induces some consumers to shift their purchases to the off-peak flight even when the firm cannot anticipate which flight is off peak. We then generalize Dana's model by assuming that some customers are fully informed while others observe only the prices for their preferred departure time. We then show that as the fraction of informed consumers increases, airlines' equilibrium capacity falls and airlines' load factors increase. This holds in both competitive and monopoly markets, but effect is strongest when the market is competitive. The model predicts that a decrease in market frictions leads to an increase in load factors, an associated decline in capacity utilization, and an unambiguous increase in social welfare.

We estimate a reduced-form regression of airline directional airport-pair load factor on metropolitan area Internet penetration. Quarterly airline load factors come from the Bureau of Transportation Statistics, and annual Internet penetration for 1997 to 2003 comes from the Computer Use and Ownership Supplement to the Consumer Population Survey. Because passengers do not necessarily live in just one metropolitan area, we use the Department of Transportation's Origin and Destination Survey to constructed a weighted average measure of the Internet penetration in the cities in which the passengers travel itineraries began, since this is where they most likely purchased their tickets. Finally by using fixed effects we are able to identify the impact of the Internet on load factors controlling for market and airport characteristics, airline characteristics, and time. That is, we test whether differences in the rate of change of Internet penetration explain differences in the rate of change of airline airport-pair load factors.

The next section of the paper discusses the related literature in airline pricing

\footnotetext{
${ }^{1}$ Other papers that examine stochastic peak-load pricing are Carlton (1977) and Brown and Johnson (1969), but these papers consider a social planner who is restricted to uniform prices. Dana (1999a) shows that the competitive equilibrium prices in these models are generally nonuniform.
} 
and the economics of the Internet. Section 3 presents the theoretical model. Section 4 describes our data. Section 5 describes the estimation and Section 6 concludes.

\section{The Related Literature}

The theoretical literature on capacity decisions and demand uncertainty with price rigidities is extensive. The first set of papers in this category is the stochastic peakload pricing literature (Brown and Johnson, 1969 and Carlton, 1977). In these models, firms choose capacity and set prices for multiple flights before learning demand. After demand is realized, consumers purchase their preferred product subject to availability. Stochastic peak load pricing predicts that capacity will be underutilization at off-peak times because prices are set before demand is realized.

Note that there is less incentive for consumers to switch from a peak flight to an off-peak flight when firms use uniform prices. By using price dispersion, firms can increase demand-shifting. The earliest paper on price dispersion as a response to demand uncertainty is Prescott (1975) who considered a simple competitive model with a single good. Several papers in the industrial organization literature have built on Prescott's work, including Dana (1998, 1999a, and 1999b), and Deneckere, Marvel, and Peck (1997). ${ }^{2}$ In particular, Dana (1999a) shows that price dispersion increases demand shifting and in so doing increases social welfare by improving the allocation of consumers to available capacity.

Few papers have tried to empirically test the Prescott model. One exception is Escobari and Gan (2007) who directly test the hypothesis that price dispersion is induced by demand uncertainty. They also show that airline price dispersion increases with competition as implied by Dana (1999a and 1999b).

Another exception is Puller, Sengupta, and Wiggins (2007). They have detailed data on airline tickets purchased through a single computer reservation system which allows them to ask what portion of fare differences are associated with restrictions and what portion represent pure dispersion of the type predicted by Dana (1999b). They find modest support for Dana (1999b) and strong support for models based on second-degree price discrimination.

While our paper does not directly test the Prescott model, we test an important implication of the theory. Namely, we test the prediction that capacity utilization increases when consumers are better informed about the available products' and their prices.

\footnotetext{
${ }^{2}$ The Prescott model has also been widely applied in monetary economics (see Eden, 1990, 1994, Lucas and Woodford, 1993) and labor economics (see Weitzman, 1989).
} 
The empirical literature on the impact of the Internet is extensive. Many papers have compared online markets to traditional markets, and in particularly, focused on price levels and price dispersion (see Ellison and Ellison, 2006). Brynjolfsson and Smith (2000) report that compact disk and book prices are 9 to $16 \%$ lower in online markets and that price dispersion is slightly smaller. It isn't immediately apparent whether price differences reflect differences in costs, or differences in margins, but Brynjolfsson and Smith conclude the significant sources of heterogeneity, such as brand and reputation, are not diminished by Internet competition. Other papers (for example, Clay, et. al., 2001, and Baye, Morgan, and Scholten 2004) have found less evidence of price declines, but all of these papers find consistent evidence that online price dispersion is quite large, even compared to traditional markets.

A handful of papers have considered the impact of the Internet on prices in the airline industry. Clemons, Hann, and Hitt (2002) and Chen (2002) find that prices available from online travel agents are just as dispersed as those available from traditional offline travel agents. Using national data on Internet use, Verlinda and Lane (2004) find that increased Internet usage is associated with greater differences between restricted and unrestricted fares. Using a cross section of airline tickets purchased both online and offline, Sengupta and Wiggins (2007) find that tickets sold online have lower average prices and that increases in the share of tickets purchased online implies lower offline fares and lower price dispersion. Finally, using metropolitan area Internet access and a differences in differences estimation strategy similar to ours, Orlov (2007) examines the impact of Internet access on prices and price dispersion in the airline industry. He finds that increases in Internet access are associated with decreases in airport-pair prices. He also finds that increases in Internet access have led to a decrease in interfirm fare dispersion, but an increase in intrafirm fare dispersion.

Several papers have tried to measure other ways in which the Internet increases consumer surplus. Brynjolfsson, Hu, and Smith (2003) show that the Internet enables consumers to obtain hard-to-find books. Ghose, Telang, and Krishnan (2005) argue that the Internet increases the resale value of new products, and Ghose, Smith, and Telang (2006) show that the Internet facilitates the market for used books. Other papers have emphasized that the Internet reduces consumers' offline transportation costs. For example, Forman, Goldfarb, and Greenstein (2005) and Forman, Ghose, Goldfarb (2007) conclude that the Internet reduces consumer travel and transportation costs in the market for books.

Undoubtedly, the Internet has also directly impacted firms' costs. For example, the Internet probably helps firms improve their demand forecasts, reduce their communications costs, and more efficiently monitor their workers and suppliers. However, 
to our knowledge this is the first paper to show that increasing consumers access to the Internet can lower firms' costs.

Our paper is also related to empirical work on inventory management. Gaur et. al. (2005) finds that inventory turns (the cost of goods sold to inventory ration) are negatively correlated with margins and capital intensity, and positively correlated with unexpected demand (see also Roumiantsev and Netessine, 2006). Gao and Hitt (2007) consider the impact of information technology on operation decisions, however their focus is on product variety and not on inventory or capacity utilization. Cachon and Olivares (2007) show that competition increases service levels, and hence inventory ratios, in automobile dealerships. Rajagopalan and Malhotraw (2001) document trends in inventory levels and show that finished goods inventories, materials, and work-in-progress ratios have declined in most manufacturing industries, but they do not find that the evidence of greater improvements post-1980 as compared to pre-1980.

Finally, in the macroeconomics literature Kahn, McConnell, and Perez-Quiros (2002) use firm level data to test the impact of information technology on the volatility of inventories. They find that information technology has lead to a reduction in aggregate output and inflation volatility. However they do not show directly that information technology lowers inventory costs.

\section{Theory}

In this section we present a generalization of the model of stochastic peak load pricing presented in Dana (1999a). This model is only one of many that share common predictions about the impact of the Internet on capacity utilization. However, as mentioned earlier, this model captures both the role of market power and price rigidities on the way in which airline seats are allocated.

Suppose there are two possible departure times, $A$ and $B$, and that a finite measure $N$ of consumers have heterogeneous departure time preferences and heterogeneous willingness to pay for their preferred departure time. Suppose consumers valuations for their preferred departure time, $V$, are identical, but the disutility from traveling at their least preferred time, $w$, is distributed with cummulative distribution function $F(w)$ and probability density function $f(w)$ satisfying the monotone

hazard rate condition (i.e., $\frac{F(w)}{f(w)}$ is strictly increasing in $w$ ). Consumers' departure time preferences and the strength of their preferences, $w$, are assumed to be independently distributed.

Consumers' departure time preferences are correlated and which of the two de- 
parture times, $A$ or $B$, will be most popular is unknown to the firm. We assume either time is equally likely to be the peak and that the number of consumers who prefer the peak time is $N_{1}$, which is greater than the number who prefer the off-peak time, that is $N_{1}=N-N_{2}>N_{2}$.

The cost of capacity is $k$ and the marginal cost of carrying a passenger, conditional on having an available seat is 0 .

The timing is as follows. First, the firms set their capacity. Second, firms set their prices for their capacity at time $A$, and their prices for their capacity at time $B$. Third, the state is realized and consumers learn their departure preferences and $w$. Fourth, a fraction $\alpha$ of consumers observe all prices and a fraction $1-\alpha$ of consumers observe only the prices for their preferred departure time. Finally, in random order consumers make their purchase decisions maximizing consumer surplus subject to availability (and assuming they cannot purchase a product they don't observe). ${ }^{3}$

Following Dana (1999a), in a perfectly competitive market, the equilibrium prices are $p_{L}=k$ and $p_{H}=2 k$ and the capacity available at each price is

$$
Q_{L}=N_{2}+\left(N_{1}-N_{2}\right) \frac{\alpha F(k)}{1+\alpha F(k)}
$$

and

$$
Q_{H}=\left(N_{1}-N_{2}\right) \frac{1-\alpha F(k)}{1+\alpha F(k)}
$$

Total capacity is

$$
Q_{H}+Q_{L}=N_{2}+\left(N_{1}-N_{2}\right) \frac{1}{1+\alpha F(k)}
$$

and the capacity utilization rate (or load factor) is

$$
\frac{Q_{H}+2 Q_{L}}{2 Q_{H}+2 Q_{L}}=\frac{N_{1}+N_{2}}{2 N_{1} \frac{1}{1+\alpha F(k)}+2 N_{2} \frac{\alpha F(k)}{1+\alpha F(k)}} .
$$

Proposition 1. In a competitive market, the equilibrium load factor is decreasing in the level of market frictions, i.e., increasing in $\alpha$, and the equilibrium capacity is increasing in the level of market frictions, i.e. decreasing in $\alpha$.

Proof. Since $N_{2}<N_{1}$, the denominator in (2) is decreasing in $\alpha$, so the load factor is stictly increase in $\alpha$. Similarly (1) clearly implies equilibrium capacity is decreasing in $\alpha$.

\footnotetext{
${ }^{3}$ As in Dana (1999a) we use random, or proportional, rationing which seems more intuitive for the airline application than efficient, or parallel, rationing.
} 
Notice that social welfare increases as $\alpha$ increases. Consumers are better off. Some consumers are clearly better off because an increase in $\alpha$ makes them aware of additional products and hence increases their choice set. Also, because there are more low priced seats available, when consumers make their purchase decisions more consumers have the option to purchase low priced seats. That is, an increase in $\alpha$ increases the choice set for some consumers without effecting the others. Consumers are strictly better off. And firms continue to earn zero profits, so social welfare increases.

Also, notice that an increase in $\alpha$ decreases airlines' capacity and airlines' costs. In a competitive equilibrium, airlines still earn zero profits, so these cost savings are passed on to consumers. As $\alpha$ increases, the proportion of consumers who pay $2 k$ falls and the proportion who pay $k$ increases.

Corollary. A lower bound on the social welfare gains from an increase in $\alpha$ is one half of the cost savings associated with the decrease in equilibrium capacity.

Proof. Increasing $\alpha$ increases the number of consumers who switch from their preferred flight to an alternate flight. Social welfare increases, because for every additional consumer who switches, costs fall by $2 k$. The switchers save $k$ themselves, because they pay $k$ instead of $2 k$. While these consumers also bear a cost, because they switch voluntarily, it follows that $w<k$. Also for every consumer who switches, one consumer who does not switch pays a lower price, $k$, instead of $2 k$. So under random rationing, welfare increases by $2 k-E[w \mid w<k]>k$. The welfare increase (per switcher) is strictly greater than one half the cost savings (per switcher).

\section{Monopoly Pricing}

Now consider the monopolist's pricing problem. Following Dana (1999a), suppose that the monopolist offers at most two prices, $p_{h}$ and $p_{l}$.

Clearly without loss of generality $p_{h}=V$, so the monopolist's problem is to choose $p_{l}$, or equivalently the discount $d=V-p_{l}$, to maximize its profits where

$$
Q_{L}(d)=N_{2}+\left(N_{1}-N_{2}\right) \frac{\alpha F(d)}{1+\alpha F(d)}
$$

and

$$
Q_{H}(d)=\left(N_{1}-N_{2}\right) \frac{1-\alpha F(d)}{1+\alpha F(d)}
$$


and the monopolist maximizes

$$
\max _{d} 2 Q_{L}(d)(V-d-k)+Q_{H}(d)(V-2 k) .
$$

The first-order condition is

$$
-2\left(N_{2}+\left(N_{1}-N_{2}\right)\left(\frac{\alpha F(d)}{1+\alpha F(d)}\right)\right)+2 \frac{\alpha f(d)\left(N_{1}-N_{2}\right)}{(1+\alpha F(d))^{2}}(k-d)=0 .
$$

or

$$
-\left(N_{2}+\left(N_{1}-N_{2}\right)(1+\alpha F(d)) \frac{F(d)}{f(d)}\right)+\left(N_{1}-N_{2}\right)(k-d)=0 .
$$

When $d=k$ the left-hand side of the first-order condition is negative, so $d<k$. That is, the monopolist shifts fewer customers from the peak to the off-peak flight than would be shifted in a competitive market. This implies:

Proposition 2. All else equal, load factors are lower in a monopoly market than in a competitive market.

However, just as in the case of competitive markets, the monopolist's load factor rises and capacity falls as $\alpha$ rises. Holding $d$ fixed, it is clear from the definitions of $Q_{L}$ and $Q_{H}$ that this is true, and (3) implies that $\frac{d d}{d \alpha}>0$ so increasing in $\alpha$ induces even more switching. So we have:

Proposition 3. In a monopoly market, the equilibrium load factor is decreasing in the level of market frictions, i.e., increasing in $\alpha$, and the equilibrium capacity is increasing in the level of market frictions, i.e., decreasing in $\alpha$.

\section{Discussion}

Our model is quite stylized and does not capture import sources of variation in the airline industry that affect equilibrium capacity utilization. An important element missing from our model is variation in the degree of demand uncertainty. Airlines face tremendous variation in demand over the time of day, time of week, and time of year, and a large amount of that variation, particularly in small or "thin" markets, is difficult to forecast. If markets vary in the predictability of their demand, we would generally expect less volatile markets to have higher load factors, lower fares, and more competitors. On the other hand markets with more volatile demand should have lower load factors, higher fares, and fewer competitors. 
One obvious source of variation in aggregate demand uncertainty is the number of consumers. In a simple model in which the aggregate demand distribution is the sum of independent binomial decisions, it is well known the aggregate demand will be approximately normally distributed with a mean proportional to the number of consumers and a variance proportional to the square root of the number of consumers. So, for example, as the number of consumers grows, the average load factor for an airline whose capacity is set equal to the mean demand is clearly increasing. Even when capacity is chosen optimally, the ratio of expected sales to capacity will grow with the number of consumers.

An important question is whether the number of consumers is a market measure or a firm measure. If products are perfect substitutes (as in the model above) market size seems to be the appropriate measure. However, when airlines' products are differentiated, firm size may be a more appropriate control.

The hub and spoke system is also likely to increase load factors. By increasing density on its spokes, airlines are able to increase frequency and take advantage of size to reduce the demand uncertainty.

Other complex network scheduling decisions will also impact an airline's capacity utilization. For example, an airline may schedule one of its larger planes to fly late in the evening (typically off-peak), so that it is available at its hub in the morning (typically peak). These network scheduling problems are even more complex then it first appears because of legal and union constraints on flight crews' daily flying hours.

\section{Data}

We use four different data sets. First, we use the T100 (Form 41) database from the Bureau of Transportation Statistics. This data reports the monthly capacity and passenger traffic by airline, by directional airport-pair segment, and by aircraft type, for all the domestic passenger flights in the US from 1997 to 2003. A directional airport-pair flight is a single take-off and landing by a single airplane traveling from one airport to another. Flights that are canceled are not included in this data, only flights that are actually flown.

The airport-pair-airline unit sales and capacity data in the T100 database is used to calculate each airlines' market share in each directional airport-pair segment. It is also used to calculate the average load factor for each airline in each airportpair segment. Finally, it is used to construct a set of mutually exclusive market structure dummy variables for each airport-pair segment (Monopoly, Duopoly, and Competitive). Monopoly is set to one for markets in which the largest firm's market 
share (share of sales) exceeds $90 \%$. Duopoly is set to one for markets in which no one firm's market share exceeds $90 \%$, but that the largest two firms' combined share exceeds $90 \%$ or the two largest firms' combined market share exceeds $80 \%$ and the third largest firm's share is less than $10 \%$. Competitive is set to one in every other market.

Second, we use the Computer Use and Ownership Supplement to the Consumer Population Survey (CPS) in 1997, 1998, 2000, 2001, and 2003 to measure Internet penetration for every major metropolitan areas. The data for 1999 and 2002 are interpolated. The survey asks about Internet access at home, school, and business. For each metropolitan area we compute the fraction of respondents answering yes to any of these Internet access questions using sample weights provided by the CPS.

Third, we use Origin and Destination Survey (DB1B) market database. This is a $10 \%$ sample of all passenger tickets purchased in each quarter for each year in our sample (1997 to 2003) and includes the airline, the quarter in which the ticket was used, the number of passengers on the ticket, the fare, the market origin (for the passenger), and market destination (for the passenger), and the itinerary (the individual flight segments flown). The DB1B market database includes two entries for each roundtrip ticket and just one entry for each one way ticket. That is, a market is defined by the passenger's origin and destination (as opposed to the specific route that he or she flies). Importantly, the database identifies which entries are the outbound and return portions of round-trip tickets, so the database also allows us to identify the ticket origin, that is where the passenger starting their travel when they fly round-trip. However, Southwest airlines reports all of its roundtrip ticket sales as two one-way tickets, so we cannot identify the ticket origin for Southwest passengers in the DB1B market database.

For simplicity we restrict the DB1B database to itineraries with at most one stop on each directional market. We also dropped itineraries where one of the carriers on any segment was unknown, itineraries with "top-coded" fares, and itineraries with fares below $\$ 25$ in 2000 dollars. We also dropped very short trips, with travel distance less than 50 miles.

Using this data, we construct the average fare by airline-airport-pair segment. The fare paid for each market in the DB1B market database is divided between the segments flown in proportion to the distance flown and the segment fares are averaged across passengers who flew that airline-airport-pair segment. Note that because the fare is allocated by distance flown, this is an imperfect measure of the actual incremental cost to consumers of flying on the segment.

Note that passengers on a particular flight do not necessarily purchase their tickets in the city that is the flight's point of origin. Most notably, many passengers 
are returning home on the return portion of a round-trip ticket, so passengers are just as likely to have purchased the ticket in the city that is the flight's destination. Still other passengers will be flying on connecting flights from an origination airport that was different than the airport where the airplane originated and/or to a final destination that is different than the airport where the plane lands. The distinction is important, because our hypothesis is that the level of Internet access where passengers book their tickets, not where the plane originates, is what effects how much information they have.

For this reason, we also use the DB1B database of passenger itineraries to find the number of passengers on each flight who originated their travel in each US airport. Passengers flying non-stop on the outbound segment of their itinerary are counted as having originated their travel in the airport at which the plane started it's flight. Passengers flying non-stop on the return segment of their itinerary are counted as having originated their travel in the airport at which the plane ends it's flight. While these may constitute a large fraction of the passengers, other passengers with connecting itineraries will have originated their travel at airports other than the one at which the plane started and ended its flight.

We use these passenger numbers as weights and construct a measure Internet penetration which is customized to each airline-airport-pair segment. For each airlineairport-pair segment and each quarter, we compute the average Internet penetration for passengers on that flight as the weighted average of the metropolitan area Internet penetration where the weights are the portion of the planes passengers whose itineraries originated at an airport in that metropolitan area. As noted above, travel by passengers on Southwest Arline's is recorded as a one-way ticket even when they fly round trip, so we are unable to determine the point of origin for Southwest Airline's roundtrip passengers. For this reason, we omit Southwest Airline's flights from our regressions.

Finally, we use the Official Airline Guide to obtain a complete schedule of each airline's flights by directional airport-pair, aircraft type, and time of day. The OAG allows us to calculate the fraction of each airline's flights which are at different times of the day. And since the data include the aircraft type, we can calculate these fractions at the aircraft level. When airlines use multiple aircraft types on the same segment, this means we can get a more precise measure of the time of day of airline's flights. This allows us to measure whether Internet penetration has more affect on peak or off-peak load factors.

After matching these four datasets, we further limit our sample to traffic on the 20 largest airlines and between the 75 largest airports in the US. These 20 airlines are listed in Table 1. We also removed the 4th quarter of 2001 from our sample 
because of the terrorist attacks on $9 / 11 / 2001$ which severely disrupted service and air travel in that quarter. This leaves us with 101618 quarterly observations.

Table 2 lists descriptive statistics for each of the variables we use in our analysis.

\section{Estimation}

Prices, market structure, sales, capacity, and capacity utilization are all endogenous variables that vary with exogenous characteristics of each airline and airport-pair market. In principle, we could test our hypothesis with a reduced form regression of capacity utilization on weighted Internet access and these exogenous characteristics. However we observe very few exogenous market characteristics.

Instead, we control for many of these omitted exogenous variables with directional airline-segment and airline-quarter fixed effects. The airline-segment fixed effects control for non time-varying airline, route, metropolitan area, and airport characteristics, as well as airline-airport characteristics such as the presence of a hub or local brand loyalty. The airline quarter fixed effects control for time-varying airline characteristics, such as brand loyalty, but not time-varying characteristics that are specific to a given city or segment.

In addition, we estimate the same regression using fare, market structure, market share, and available seats (capacity) as control variables. While these variables are endogenous, they should be correlated with other unobserved exogenous variables. Seeing that our results are robust to the inclusion of these endogenous variables makes us more confident that our results are not a consequence of correlation between Internet use and other time-varying market characteristics.

Furthermore, these controls give us the opportunity to cautiously test whether market power diminishes the impact of the Internet as predicted by the theory. We say cautiously of course because we do not have any instruments for market structure, and, given our fixed effects, a valid instrument for market structure would need to be correlated with changes in market structure over time. We can also see what impact market size and price have on load factors.

Table 3 contains our first set of regressions. We regress the log of the quarterly, airline, directional, airport-pair load factor on the log of Internet access, which is specific to each directional route and each quarter (the weights change quarterly, though Internet changes annually). This Internet variable is a weighted average of the metropolitan area Internet penetration where the weights are the proportion of passengers flying on each airline, directional, airport-pair segment whose travel originated in each metropolitan area. For example, a passenger on the return portion of a non-stop, round-trip flight will have originated his or her travel in the segment's 
destination airport, while a passenger on the second leg of the outbound portion of connecting, round-trip flight will have originated his or her travel at the airport where his or her first leg began.

We use a log-log specification because we believe that the impact of an increase in Internet penetration is greatest when the level of Internet penetration is small. That is, the early adopters of the Internet are more likely to be air travelers than the late adopters.

Also, while our unit of observation is an airline, directional, airport-pair quarter, the economic unit of observation that is of interest is capacity. Particularly for making welfare calculations, we would like to put more weight on airport-pairs with more flights and more available seats. So throughout the paper, we weight our observations by the number of available seats.

Before interpreting our results, it is useful to begin by asking what are the unobserved sources of variation which we are not controlling for with our fixed effects? The most obvious are segment specific variation in cost and variation in demand. The later includes variation in the size of market demand as well as variation in the elasticity of demand and extent of demand uncertainty. Other potential sources of variation are changes over time in market structure, as well as changes in the degree of firm rivalry and the threat of entry. While market structure is endogenous and likely to be correlated with unobservable changes in demand, it is worth pointing out that our market structure variables could not control for the later two sources of variation even if they were exogenous.

In Column 1 of Table 3 we report our first specification with the fixed effects but without any other controls. In Column 2 we include only market structure controls. In Column 3 we add available seats as a control and Column 4 we add fare as a control. The coefficient on Intenet access is positive, statistically significant, and remarkably constant across these specifications.

The final three columns report the results when the sample is divided up by market structure. In these regressions, the Internet has the largest impact on duopoly markets, where it is statistically significant. The impact of the Internet on monopoly markets is smaller and insignificant, a result which is inconsistent with the theory. However, the impact of the Internet on competitive markets is negative and insignificant, a puzzling result given the theory.

In addition to being endogenous, there is another problem with the market structure measure. Market structure may not be capturing market power because airportpairs that are served by a single non-stop carrier which face significant competition from airlines offering connecting service. In the future we plan to address this by using a market structure variable based on passenger origin and destination markets 
as opposed to airplane segments.

In our regressions, we find that load factors are lower in more concentrated markets. Firms with market power are likely to have higher margins which increases the incentive to hold speculative capacity. While market structure is endogenous, it is likely that much of the variation in market structure over time will be driven by financial conditions of airlines and demand changes in other markets. However, clearly these coefficients must be interpreted cautiously.

We find that load factors are higher for firms with a larger market share within each market. This is consistent with the intuition that the variance of demand uncertainty falls relative to the mean as the market size grows, so the incentive to hold speculative capacity falls with size. Or more simple put, it is easier to match the number of planes to the size of the market when the market is larger.

However, we find that load factors are lower for firms with more available seats. We expected the opposite result. Variation in demand or costs (that we don't observe but firms do observe) should move capacity and load factors in the same direction. Instead, we are seeing the effect we would expect to see if seats were exogenous: exogenous increases in capacity reduce load factors. The simplest interpretation of these results is that airlines are slow to adjust capacity in response to shifts in demand. However, it is also the case that while seats is clearly a measure of market size, it is an airline specific measure. It is likely that these shifts in demand are due to capacity adjustments by rivals. This is consistent with the fact that the coefficient on seats in the monopoly regressions in statistically insignificant.

Finally, we find that higher fares lead to lower load factors, which is consistent with the intuition that holding costs fixed, airlines with higher fares are more willing to hold speculative capacity. While it is clear that the biggest source of variation in fare levels is likely to be costs, these results are not surprising since the variation in fares over time is less likely to be do to route-specific shifts in costs, and more likely to be because of segment-specific changes in demand, rival behavior, or the threat of entry.

Adding the fare as a control variable reduces the coefficient on the Internet variable from .060 to .049. That is, holding fare fixed, Internet penetration has a positive and significant effect on load factors. Fare is clearly negatively correlated with Internet penetration. For starters, Internet penetration can lead to increased competition. And in addition, Internet penetration can lead to lower load factors, lower costs, and hence lower fares.

In Table 4, we report our second set of regressions. If uncertainty is the the result of identically and independently distributed consumer demand, then it will be normally distributed with a variance to market size ratio which is decreasing in 
market size. As a consequence, load factors should be higher on thicker routes and increases in Internet penetration should have less impact on load factors. We test this by interacting Internet penetration with available seats. We find, as expected, that Internet penetration has a larger effect on smaller markets.

Table 5 reports our final set of regressions in which we include the OAG schedule data to measure of the fraction of each airline's flights which depart at different times of the day. First, we use the DOT aircraft data to construct the load factor by airline, aircraft, directional airport-pair. Then we use the OAG data to measure the proportion of the flights that depart before $10 \mathrm{AM}$, between $10 \mathrm{AM}$ and $4 \mathrm{PM}$, and after 4 PM. Note that by matching the aircraft type with the CAB data, our estimates are more accurate whenever airlines use multiple aircraft types on the same directional, airport-pair segment. Note that Table 5 uses observations only through 2001 (we are still in the process of obtaining and utilizing the 2002 and 2003 OAG data).

We find that load factors are highest on departures between $10 \mathrm{AM}$ and $4 \mathrm{PM}$ and lowest before $10 \mathrm{AM}$, though after $4 \mathrm{PM}$ is about the same. We find that Internet penetration has a larger and statistically more significant impact on load factors when we control for time of day. However, surprisingly, we do not find evidence that the impact of the Internet is greatest during peak demand periods.

We tried one additional set of regressions which we did not include in the paper. In these regressions we also include airport-quarter fixed effects for both the origin and destination airports. These fixed effects control for many additional sources of unobserved variation, including most segment-specific demand and cost characteristics. However, these fixed effects also eliminate the biggest source of variation in our Internet measure, namely the Internet penetration rates in the metropolitan areas where the plane's origin and destination airports are located. Hence, our Internet variable is identified only from changes in Internet use by connecting passengers, those whose point of origin was neither the segment origin nor the segment destination. We did not find evidence that the Internet increases load factors in these regressions. While this increases our concern that our results are due to an omitted variables, it is also likely that we do not have enough remaining variation in our Internet measure.

We find that Internet penetration has a positive and statistically significant effect on load factors. Using Table 3, the elasticity of Internet penetration on load factor is 0.054 . That is, each percentage point increase in Internet penetration increases load factors by $.054 \%$, and a doubling in Internet penetration increases load factors by $3.8 \%$. From a starting point of $69 \%$, this implies load factors would increase to $71.6 \%$. In our sample period, Internet access more than doubled in many cities while 
load factors have increased from about $69 \%$ to $73 \%$. So the Internet appears explain most, if not all, of the increase in airline load factors during our sample period.

US airline industry passenger flying operations and maintenance costs were $\$ 40$ billion in 2000, so an increase of $2.6 \%$ in load factor represents a $2.6 \%$ decrease in these costs or over $\$ 1$ billion in cost savings every year.

\section{Social Welfare}

Because our Internet variable is a noisy measure of how many consumers are using the Internet to choose flights and/or purchase their tickets, our estimates are likely to understate the total cost savings associated with the Internet. In particular, since we cannot identify perfectly where consumers purchase their tickets, we aren't measuring the impact of the Internet on those passengers who purchase their tickets elsewhere. So it is possible that the cost savings could be even larger. On the other hand, it remains possible that the results in Table 3 are the result of an omitted variable bias. Also, since we are attributing almost all of the growth in load factors to the Internet, it is unlikely the Internet had much more impact.

Another serious concern is that this cost savings need not all represent a welfare gain. Some of these cost savings may have been offset by decreases in consumer surplus as consumers elect to travel at less convenient times. Without estimates of the demand function, we cannot measure the lost in consumer surplus associated with consumers switching departure times. However, we argued that in our model (see Section 3 above) the social welfare gains are at least one half of the cost savings. And, if the inconvenience of fly off-peak, $w$, is small, the gains could be significantly higher.

However, the model may overstate the the welfare gains. First, in a competitive model with no aggregate uncertainty or with market clearing spot prices, the impact of a reduction in market frictions would also be to shift demand, but the impact on welfare would be smaller. For example, in a competitive peak-load pricing model that exhibits some under-utilization of capacity, the off-peak price will be $c$ and the peak-price will be $2 k+c$. So the welfare gain for each switcher is $2 k-E[w \mid w<2 k]$ which is strictly positive, but significantly smaller than $2 k-E[w \mid w<k]$. However, this is not consistent with casual evidence. Airline fares for ex post off-peak flights do not generally equal marginal cost but instead are significantly higher.

Second, increasing load factors also increases passenger congestion (though it probably lowers airport congestion). And we have no way of measuring the impact

of congestion on consumers surplus. 
And finally third, we have considered a simply model in which seats are not rationed. In a more general model in which there was some limit on market prices or in which demand is lumpy, a reduction in market frictions could theoretically lead to an increase in rationing. With rationing, it no longer follows that the disutility of consumers who switch must be bounded by the difference in fares. ${ }^{4}$

With these caveats in mind, our estimates imply an ongoing social welfare gain of at least $\$ 500$ million every year from the increase in Internet penetration that occurred just in the 1997 to 2003 period.

\section{Conclusion}

The Internet has clearly made it easier for consumers to become informed about alternatives to their preferred time of departure, carrier, or destination. A customer buying a ticket on an airline's web site, such as United.com, or on a third party travel services web site, such as Expedia.com, selects their itinerary from a much larger set of options than those that are available to a customer making a reservation on the telephone. The increase in consumers' information has helped airlines to reduce their capacity costs, and airlines appear to be well aware of this. On United Airlines' web site even after choosing their itinerary from the wide selection available, a customer is shown yet another set of lower fare options before making their final purchase decision. No doubt United is able to capture some of the surplus created when it induces consumers to switch flights, so it is interesting to note that it is United, not Expedia, which offers this feature.

We used differences Internet penetration across time and metropolitan area to identify the impact of reductions in market frictions on differences in airlines' capacity utilization rates, or load factor, across time and airport-pair segments. We found that an increase in Metropolitan area Internet access leads to an increase in load factors on flights flown by passengers whose travel begins in that Metropolitan area. That is, a flight's load factors increase faster when passengers traveling on the flight come live in cities in which internet use is increasing faster.

While increases in Internet access have lead to increases in airlines' load factors and a decrease in airlines' costs of almost $\$ 1$ billion each year, we believe that much of this cost savings has been passed on to consumers through lower prices. This is consistent with the fact that airlines did not see dramatic increases in profits during

\footnotetext{
${ }^{4}$ By rationing, we mean that no seat is available at any fare and in any face class. So while coach seats are sometimes rationed, business and first class seats are almost always available because airlines typically can use unsold seats in these classes as reward or upgrades at the last minute for their frequent fliers.
} 
this period. It is also consistent with the empirical literature (particularly Orlov, 2006) which has found that the Internet has significantly reduced average airline prices. However, whether or not the cost savings is passed on to consumers, we have argued that much of this costs savings represents an increase in social welfare. 
Table 1: Twenty Largest Airlines ${ }^{5}$

\begin{tabular}{lrr}
\hline Airline & Passengers in 2003 & Market Share \\
\hline AirTran Airways & $11,825,116$ & $2.2 \%$ \\
Alaska & $13,423,198$ & $2.5 \%$ \\
Aloha & $4,359,204$ & $0.8 \%$ \\
America West & $20,160,929$ & $3.8 \%$ \\
American & $76,170,601$ & $14.3 \%$ \\
American Eagle & $11,953,383$ & $2.2 \%$ \\
ASA (Delta) & $9,755,124$ & $1.8 \%$ \\
ATA & $9,898,834$ & $1.9 \%$ \\
Comair & $10,667,112$ & $2.0 \%$ \\
Continental & $32,260,432$ & $6.0 \%$ \\
Delta & $79,555,539$ & $14.9 \%$ \\
ExpressJet (Continental \& Delta) & $10,600,616$ & $2.0 \%$ \\
Hawaiian & $5,777,049$ & $1.1 \%$ \\
Horizon Air (Alaska Airlines) & $4,688,931$ & $0.9 \%$ \\
Mesaba Airlines (Northwest) & $5,957,820$ & $1.1 \%$ \\
Northwest & $44,807,607$ & $8.4 \%$ \\
Southwest & $83,560,507$ & $15.7 \%$ \\
United & $58,000,549$ & $10.9 \%$ \\
US Airways & $40,378,900$ & $7.6 \%$ \\
\hline
\end{tabular}

\footnotetext{
${ }^{5}$ Regional airlines typically provide connecting service for one or more major airline on a contract basis. The major airline, or airlines, with which each regional airline is partnered is shown in parentheses.
} 
Table 2: Descriptive Statistics (101618 Quarterly Observations)

\begin{tabular}{lrrrr}
\hline Variable & Mean & Std. Dev. & Min & Max \\
\hline Load Factor & 0.672 & 0.164 & 0.003 & 1.000 \\
Market Share & 0.584 & 0.368 & 0.000 & 1.000 \\
Monopoly & 0.398 & 0.490 & 0.000 & 1.000 \\
Duopoly & 0.443 & 0.497 & 0.000 & 1.000 \\
Competitive & 0.159 & 0.366 & 0.000 & 1.000 \\
Weighted Internet & 0.532 & 0.174 & 0.083 & 0.854 \\
Fare & 152.158 & 78.014 & 4.829 & 1389.242 \\
Seats & 42536.890 & 43749.750 & 30.000 & 419644.000 \\
\hline
\end{tabular}


Table 3. Regression Results

With Airline-Segment and Airline-Quarter Fixed Effects

\begin{tabular}{|c|c|c|c|c|c|c|c|}
\hline \multirow{2}{*}{ Dependent Variable: } & \multicolumn{7}{|c|}{ LOG (Load Factor) } \\
\hline & \multicolumn{4}{|c|}{ All Routes } & \multirow{2}{*}{$\begin{array}{c}\text { Monop. } \\
\text { Segments } \\
(5)\end{array}$} & \multirow{2}{*}{$\begin{array}{c}\begin{array}{c}\text { Duop. } \\
\text { Segments }\end{array} \\
(6)\end{array}$} & \multirow{2}{*}{$\begin{array}{c}\text { Compet. } \\
\text { Segments } \\
(7)\end{array}$} \\
\hline & (1) & (2) & (3) & (4) & & & \\
\hline LOG (WEIGHTED INTERNET) & $.054^{* * *}$ & $.054^{* * *}$ & $.060^{* * *}$ & $.049^{* *}$ & .026 & $.071^{* *}$ & -.059 \\
\hline & $(.020)$ & $(.020)$ & $(.020)$ & $(.019)$ & $(.027)$ & $(.029)$ & $(.041)$ \\
\hline MONOPOLY & & $\begin{array}{l}-.047^{* * *} \\
(.007)\end{array}$ & $\begin{array}{l}-.066^{* * *} \\
(.007)\end{array}$ & $\begin{array}{l}-.062^{* * *} \\
(.007)\end{array}$ & & & \\
\hline DUOPOLY & & $\begin{array}{l}-.020^{* * *} \\
(.005)\end{array}$ & $\begin{array}{l}.024^{* * *} \\
(.004)\end{array}$ & $\begin{array}{l}.018^{* * *} \\
(.004)\end{array}$ & & & \\
\hline MktSHARE & & $.165^{* * *}$ & $.234^{* * *}$ & $.282^{* * *}$ & $.236^{* * *}$ & $.399^{* * *}$ & $.468^{* * *}$ \\
\hline LOG (SEATS) & & $(.014)$ & $\begin{array}{l}. .046^{* * *} \\
(.004)\end{array}$ & $\begin{array}{l}. .052^{* * *} \\
(.004)\end{array}$ & $\begin{array}{l}(.003 \\
-.003 \\
(.006)\end{array}$ & $\begin{array}{l}-.105^{* * *} \\
(.007)\end{array}$ & $\begin{array}{l}-.101^{* * *} \\
(.011)\end{array}$ \\
\hline LOG (FARE) & & & & $-.144^{* * *}$ & $-.070^{* * *}$ & $-.142^{* * *}$ & $-.098^{* * *}$ \\
\hline Observations & 101618 & 101618 & 101618 & $\begin{array}{l}(.008) \\
101618\end{array}$ & $\begin{array}{l}(.013) \\
40487\end{array}$ & $\begin{array}{l}(.011) \\
44981\end{array}$ & $\begin{array}{l}(.017) \\
16150\end{array}$ \\
\hline
\end{tabular}

Notes: $\quad$ Standard errors are in parentheses. Stars denote the significance level of coefficients: *** - 1 percent, ** - 5 percent, * -10 percent. The sample includes flights on segments between top 75 airports and operated by top 20 airlines. Weighted Internet penetration by quarter, directional segment, carrier, is calculated as a weighted (by the number of passengers) measure of Internet penetration in the originating airport for all passengers on the carrier's flights on a directional segment. FARE is the average fare on a corresponding segment, calculated from the O\&D market-level data proportionally to the distance of the segment in total itinerary. Southwest Airlines is excluded because it reports all round-trip tickets as two one-way tickets, which precludes the calculation of our Internet penetration variable. Each observation is weighted by the number of available seats. 
Table 4. Regression Results

Internet-Seat Interactions

With Airline-Segment and Airline-Quarter Fixed Effects

\begin{tabular}{|c|c|c|c|c|c|c|c|}
\hline \multirow[t]{3}{*}{ Dependent Variable: } & \multicolumn{7}{|c|}{ LOG (Load Factor) } \\
\hline & \multicolumn{4}{|c|}{ All Routes } & \multirow{3}{*}{$\begin{array}{c}\text { Monop. } \\
\text { Segments }\end{array}$} & \multirow{3}{*}{$\begin{array}{c}\begin{array}{c}\text { Duop. } \\
\text { Segments }\end{array} \\
(6)\end{array}$} & \multirow{2}{*}{$\begin{array}{c}\text { Compet. } \\
\text { Segments } \\
(7)\end{array}$} \\
\hline & (1) & (2) & (3) & (4) & & & \\
\hline LOG (WEIGHTED INTERNET) & & & & & & & \\
\hline * I (SEATS IN $1^{\text {ST }}$ QUARTILE) & $.069^{* * *}$ & $.051^{* *}$ & $.103^{* * *}$ & $.089^{* * *}$ & .044 & $.099^{* * *}$ & .061 \\
\hline & $(.021)$ & $(.021)$ & $(.022)$ & $(.021)$ & $(.029)$ & $(.032)$ & $(.045)$ \\
\hline * I (SEATS IN $2^{\mathrm{ND}}$ QUARTILE) & $.056^{* * *}$ & $.050^{* *}$ & $.071^{* * *}$ & $.060^{* * *}$ & .027 & $.074^{* *}$ & -.015 \\
\hline & $(.019)_{* * *}$ & $(.020)$ & $(.020)_{* * *}$ & $(.019)$ & $(.027)$ & $(.029)$ & $(.043)$ \\
\hline * I (SEATS IN $3^{\text {RD }}$ QUARTILE) & $.051^{* * *}$ & $.050^{* *}$ & $.058^{* * *}$ & $.047^{* *}$ & .027 & $.063^{* *}$ & -.062 \\
\hline * I (SEATS IN $4^{\mathrm{TH}}$ QUARTILE) & $\begin{array}{l}(.019) \\
.056^{* * *}\end{array}$ & $\begin{array}{l}(.020) \\
.058^{* * *}\end{array}$ & $\begin{array}{l}(.020) \\
.057^{* * *}\end{array}$ & $\begin{array}{l}(.019) \\
.047^{* *}\end{array}$ & $\begin{array}{c}(.027) \\
.019\end{array}$ & $\begin{array}{l}(.029) \\
.070^{* *}\end{array}$ & $\begin{array}{l}(.041) \\
-.045\end{array}$ \\
\hline MONOPOLY & $(.020)$ & $\begin{array}{l}(.021) \\
-.048^{* * *} \\
(.007)\end{array}$ & $\begin{array}{l}(.021) \\
-.066^{* * *} \\
(.007)\end{array}$ & $\begin{array}{l}(.020) \\
-.062^{* * *} \\
(.007)\end{array}$ & $(.028)$ & $(.029)$ & $(.040)$ \\
\hline DUOPOLY & & $\begin{array}{l}-.020^{* * *} \\
(.005)\end{array}$ & $\begin{array}{l}-.024^{* * *} \\
(.004)\end{array}$ & $\begin{array}{l}-.018^{* * *} \\
(.004)\end{array}$ & & & \\
\hline MktSHARE & & $\begin{array}{l}.167^{* * *} \\
(.015)\end{array}$ & $\begin{array}{l}.235^{* * *} \\
(.015)\end{array}$ & $\begin{array}{l}.283^{* * *} \\
(.015)\end{array}$ & $\begin{array}{l}.239^{* * *} \\
(.067)\end{array}$ & $\begin{array}{l}.398^{* * *} \\
(.019)\end{array}$ & $\begin{array}{l}.474^{* * *} \\
(.042)\end{array}$ \\
\hline LOG (SEATS) & & & $\begin{array}{l}-.053^{* * *} \\
(.004)\end{array}$ & $\begin{array}{l}-.058^{* * *} \\
(.004)\end{array}$ & $\begin{array}{l}-.007 \\
(.006)\end{array}$ & $\begin{array}{l}-.107^{* * *} \\
(.007)\end{array}$ & $\begin{array}{l}-.117^{* * *} \\
(.011)\end{array}$ \\
\hline LOG (FARE) & & & & $\begin{array}{l}-.143^{* * *} \\
(.008)\end{array}$ & $\begin{array}{l}-.069^{* * *} \\
(.013)\end{array}$ & $\begin{array}{l}-.143^{* * *} \\
(.011)\end{array}$ & $\begin{array}{l}-.100^{* * *} \\
(.017)\end{array}$ \\
\hline Observations & 101618 & 101618 & 101618 & 101618 & 40487 & 44981 & 16150 \\
\hline
\end{tabular}

Notes: $\quad$ Standard errors are in parentheses. Stars denote the significance level of coefficients: $* * *-1$ percent, $* *$ - 5 percent, $*-10$ percent. The sample includes flights on segments between top 75 airports and operated by top 20 airlines. Weighted Internet penetration by quarter, directional segment, carrier, is calculated as a weighted (by the number of passengers) measure of Internet penetration in the originating airport for all passengers on the carrier's flights on a directional segment. FARE is the average fare on a corresponding segment, calculated from the O\&D market-level data proportionally to the distance of the segment in total itinerary. Southwest Airlines is excluded because it reports all round-trip tickets as two one-way tickets, which precludes the calculation of our Internet penetration variable. Each observation is weighted by the number of available seats 


\section{Table 5: Internet Penetration Weighted by Passenger Point of Origin with Time of Day Controls}

Column (3) includes airline-segment and airline-quarter fixed effects. The last three columns present estimates of the main specification after dividing the sample based on market structure.

\begin{tabular}{|c|c|c|c|c|}
\hline \multirow{2}{*}{ Dependent Variable: } & \multicolumn{3}{|c|}{ LOG (Load Factor) } & \multirow[b]{2}{*}{$\begin{array}{l}\text { Compet. } \\
\text { Segments }\end{array}$} \\
\hline & All Segments & $\begin{array}{l}\text { Monop. } \\
\text { Segments }\end{array}$ & $\begin{array}{c}\text { Duop. } \\
\text { Segments }\end{array}$ & \\
\hline MONOPOLY & ${ }_{-0.074^{* * *}}^{(1)}$ & (2) & (3) & (4) \\
\hline DUOPOLY & $\begin{array}{l}(0.010) \\
-0.024^{* * *} \\
(0.006)\end{array}$ & & & \\
\hline MktSHARE & $\begin{array}{l}0.262^{* * *} \\
(0.018)\end{array}$ & $\begin{array}{l}0.354^{* * *} \\
(0.070)\end{array}$ & $\begin{array}{l}0.298^{* * *} \\
(0.023)\end{array}$ & $\begin{array}{l}0.322^{* * *} \\
(0.038)\end{array}$ \\
\hline LOG (FARE) & $\begin{array}{l}-0.165^{* * *} \\
(0.011)\end{array}$ & $\begin{array}{l}-0.104^{* * *} \\
(0.016)\end{array}$ & $\begin{array}{l}-0.115^{* * *} \\
(0.015)\end{array}$ & $\begin{array}{c}0.013 \\
(0.016)\end{array}$ \\
\hline LOG (SEATS) & $\begin{array}{l}0.009^{* * *} \\
(0.002)\end{array}$ & $\begin{array}{l}0.012^{* * *} \\
(0.002)\end{array}$ & $\begin{array}{l}0.006^{* * *} \\
(0.002)\end{array}$ & $\begin{array}{l}0.017^{* * *} \\
(0.004)\end{array}$ \\
\hline Share $10 \mathrm{AM}$ to $4 \mathrm{PM}$ & $\begin{array}{l}0.131^{* * *} \\
(0.007)\end{array}$ & $\begin{array}{l}0.118^{* * *} \\
(0.009)\end{array}$ & $\begin{array}{l}0.129^{* * *} \\
(0.010)\end{array}$ & $\begin{array}{l}0.162^{* * *} \\
(0.016)\end{array}$ \\
\hline Share after $4 \mathrm{PM}$ & $\begin{array}{l}0.029^{* * *} \\
(0.007)\end{array}$ & $\begin{array}{c}0.012 \\
(0.010)\end{array}$ & $\begin{array}{l}0.026^{* *} \\
(0.012)\end{array}$ & $\begin{array}{l}0.062^{* * *} \\
(0.019)\end{array}$ \\
\hline Internet * Before $10 \mathrm{AM}$ & $\begin{array}{l}0.088^{* * *} \\
(0.024)\end{array}$ & $\begin{array}{l}0.135^{* * *} \\
(0.035)\end{array}$ & $\begin{array}{l}0.044 \\
(0.037)\end{array}$ & $\begin{array}{l}-0.012 \\
(0.063)\end{array}$ \\
\hline Internet * $10 \mathrm{AM}$ to $4 \mathrm{PM}$ & $\begin{array}{l}0.090^{* * *} \\
(0.025)\end{array}$ & $\begin{array}{l}0.131^{* * *} \\
(0.035)\end{array}$ & $\begin{array}{c}0.037 \\
(0.036)\end{array}$ & $\begin{array}{c}0.009 \\
(0.063)\end{array}$ \\
\hline Internet * After 4 PM & $\begin{array}{l}0.067^{* * *} \\
(0.024)\end{array}$ & $\begin{array}{l}0.103^{* * *} \\
(0.034)\end{array}$ & $\begin{array}{c}0.014 \\
(0.037)\end{array}$ & $\begin{array}{l}-0.007 \\
(0.062)\end{array}$ \\
\hline $\begin{array}{l}\text { Airline-Segment and Airline- } \\
\text { Quarter Fixed Effects }\end{array}$ & Yes & Yes & Yes & Yes \\
\hline Observations & 131989 & 55811 & 56184 & 19994 \\
\hline
\end{tabular}

Notes: Standard errors are in parentheses. Asterisks denote the significance level of coefficients: *** 1 percent, ** 5 percent, * - 10 percent. The sample includes flights on segments between top 75 airports and operated by top 20 airlines. Weighted Internet penetration by quarter, directional segment, airline, is calculated as a weighted average (by the number of passengers) of Internet penetration in the originating airport for all passengers traveling on the carrier's directional segment. FARE is the average fare on a corresponding segment, calculated from the O\&D market-level data proportionally to the distance of the segment in total itinerary. Southwest Airlines is excluded because Southwest reports its round-trip tickets as two one-way tickets, and this practice prevents use from calculating the weighted Internet penetration for passengers on their flights. 
Table 6: US Airline Average Load Factor

\begin{tabular}{lr}
\hline Year & Load Factor \\
\hline 1996 & 0.681 \\
1997 & 0.691 \\
1998 & 0.702 \\
1999 & 0.698 \\
2000 & 0.709 \\
2001 & 0.692 \\
2002 & 0.702 \\
2003 & 0.728 \\
2004 & 0.744 \\
2005 & 0.769 \\
2006 & 0.789 \\
\hline
\end{tabular}




\section{References}

[1] Baye, Michael R., John Morgan and Patrick Scholten (2004), "Price Dispersion in the Small and the Large: Evidence from an Internet Price Comparison Site," Journal of Industrial Economics.

[2] Brown, G., Jr. and Johnson, M. B. (1969), "Public Utility Pricing and Output Under Risk," American Economic Review, Vol. 59, pp. 119-128.

[3] Brynjolfsson, E. and M. Smith (2000), "Frictionless Commerce? A Comparison of Internet and Conventional Retailers," Management Science 46(4), 563-585.

[4] Brynjolfsson, E., Y. Hu and M. Smith (2003), "Consumer Surplus in the Digital Economy: Estimating the Value of Increased Product Variety," Management Science 49(11), pp. 1580-1596.

[5] Clay, Karen, Ramayya Krishnan and Eric Wol (2001) "Prices and Price Dispersion on the Web: Evidence from the Online Book Industry," Journal of Industrial Economics 49, pp. 521-540.

[6] Carlton, D. W. (1977), "Peak-Load Pricing with Stochastic Demand," American Economic Review, Vol. 67, pp. 1006-1010.

[7] Chao, H.-P. and R. Wilson (1987), "Priority Service: Pricing, Investment, and Market Organization," American Economic Review, Vol. 77, pp. 899-916.

[8] Dana Jr., J. D. (1998), "Advanced-Purchase Discounts and Price Discrimination in Competitive Markets," Journal of Political Economy, Vol. 106, pp. 395-422.

[9] Dana Jr., J. D. (1999a), "Using Yield Management to Shift Demand when the Peak Time is Unknown," Rand Journal of Economics, 30 (Autumn): 456-474.

[10] Dana Jr., J. D. (1999b), "Equilibrium Price Dispersion under Demand Uncertainty: The Roles of Costly Capacity and Market Structure," Rand Journal of Economics. 30 (Winter): 632-660.

[11] Deneckere, R, H. Marvel, and J.Peck. (1997), "Demand Uncertainty and Price Maintenance: Markdown as Destructive Competition," American Economic Review, 87 (September): 619-641.

[12] Eden, B. (1990), "Marginal Cost Pricing When Spot Markets Are Complete," Journal of Political Economy, Vol. 98 (1990), pp. 1293-1306. 
[13] Eden, B. (1994), "The Adjustment of Prices to Monetary Shocks when Trade is Uncertain and Sequential," Journal of Political Economy, 102 (June): 493-509.

[14] Ellison, G., and S. F. Ellison (2005), "Lessons about Markets from the Internet," Journal of Economic Perspectives, 19, 139-158.

[15] Escobari D., and L. Gan (2007), "Price Dispersion Under Costly Capacity and Demand Uncertainty," NBER Working Paper No. W13075.

[16] Forman, C., A. Ghose, and A. Goldfarb (2007), "Geography and Electronic Commerce: Measuring Convenience, Selection, and Price,"working paper, February.

[17] Gale, I. (1993), "Price Dispersion in a Market with Advance-Purchases," Review of Industrial Organization, Vol. 8, pp. 451-464.

[18] Gale, I, and T. Holmes, "The Efficiency of Advance-Purchase Discounts in the Presence of Aggregate Demand Uncertainty," International Journal of Industrial Organization, Vol. 10 (1992), pp. 413-437.

[19] Gale, I. and T. Holmes (1993), "Advance-Purchase Discounts and Monopoly Allocation of Capacity," American Economic Review, Vol. 83, pp. 135-146.

[20] Gao, G, and L. M. Hitt (2007), "IT and Product Variety: Evidence from Panel Data,"University of Pennsylvania, Wharton School, working paper.

[21] Gaur, V., M. L. Fisher, A. Raman. (2005), "An Econometric Analysis of Inventory Turnover Performance in Retail Services," Management Science, February, 51(2) 181-194.

[22] Ghose, A., M. Smith, and R. Telang (2006), "Internet Exchanges for Used Books: An Empirical Analysis of Product Cannibalization and Welfare Impact," Information Systems Research, 17(1), 3-19.

[23] Ghose, A., R. Telang, and R. Krishnan (2005), "Impact of Electronic Secondary Markets on Information Goods Supply Chain," Journal of MIS, 22(2), 91-120.

[24] Goldfarb, A., Electronic Commerce. Forthcoming in The New Palgrave Dictionary of Economics, 2nd Edition.

[25] Kahn, J. A, M. M. McConnell, and G. Perez-Quiros, (2002), "On the Causes of the Increased Stability of the U.S. Economy," Economic Policy Review, 8 (1). 
[26] Lucas, R. E., Jr., and, M. Woodford. (1993), "Real Effects of Monetary Shocks in an Economy with Sequential Purchases,"Working Paper no. 4250 (January), NBER, Cambridge, MA.

[27] Olivares, M., and G. Cachon (2007), "Competing Retailers and Inventory: An Empirical Investigation of U.S. Automobile Dealerships,"working paper.

[28] Orlov, E. (2007), "How Does the Internet Influence Price Dispersion? Evidence from the Airline Industry, "Northwestern University, Ph.D. dissertation.

[29] Puller, Steven L., Anirban Sengupta, and Steven N. Wiggins (2007) "Testing Theories of Price Dispersion and Scarcity Pricing in the Airline Industry," Texas A\&M University working paper.

[30] Rajagopalan, S. and A. Malhotra, (2001) "Have U.S. Manufacturing Inventories Really Decreased? An Empirical Study," Manufacturing and Service Operations Management, Vol. 3, No. 1, pp. 14-24.

[31] Roumiantsev, Serguei and Serguei Netessine (2007) "What can be learned from classical inventory models: a cross-industry empirical investigation," Manufacturing and Service Operations Management.

[32] Sengupta, Anirban and Steven N. Wiggins (2007) "Airline Pricing, Price Dispersion and Ticket Characteristics On and Off the Internet," Texas A\&M University working paper.

[33] Scott Morton, F. (2006), "Consumer Benefit from Use of the Internet." In Innovation Policy and the Economy. Vol. 6. (A.B. Jaffe, J. Lerner, and S. Stern, eds), 67-90.

[34] Prescott, E. C. (1975), "Efficiency of the Natural Rate," Journal of Political Economy, Vol. 86, pp. 1229-1236.

[35] Weitzman, M. L. (1989), "A Theory of Wage Dispersion and Job Market Segmentation." Quarterly Journal of Economics 104 (February): 121-37. 